\title{
Induction of Apoptotic Cell Death by Synthetic Naringenin Derivatives in Human Lung Epithelial Carcinoma A549 Cells
}

\author{
Eung-Ryoung LeE, ${ }^{a, b}$ Yong-Jin Kang, ${ }^{a, b}$ Hye-Yeon ChoI, ${ }^{a, b}$ Geun-Ho Kang,${ }^{a, b}$ Jung-Hyun KIm, ${ }^{a, b}$ \\ Bong-Woo KIM, ${ }^{a, b}$ Ye Sun HAN, ${ }^{b}$ Seung-Yeol NAH, ${ }^{b}$ Hyun-Dong PAIK, ${ }^{b}$ Yong-Sun PARK ${ }^{b}$ and \\ Ssang-Goo $\mathrm{CHO}^{*, a, b}$ \\ ${ }^{a}$ Department of Animal Biotechnology, RCTCP; and ${ }^{b}$ Bio/Molecular Informatics Center, Konkuk University; Seoul 143- \\ 701, Korea. Received June 4, 2007; accepted September 10, 2007
}

\begin{abstract}
Although flavonoids, which are both qualitatively and quantitatively one of the largest groups of natural products, exhibit a variety of beneficial health effects, the exact molecular mechanism of the cellular activities is still not fully explained and there currently exists a lack of evidence for any relationship between the structureactivity relationship and apoptosis-inducing activity. In order to determine the importance of the $\mathrm{OH}$ group or substitution of the 5 or carbon-7 in the diphenylpropane skeleton of flavonoids, we originally synthesized several modified naringenin derivatives, including 7-O-benzyl naringenin (KUF-1) and 7-O-(MeO-L-Leu-D-Pro-carbonylmethyl) naringenin (KUF-7). Treatment with KUF-1 or KUF-7 resulted in significant apoptosis-inducing effects concomitant with chromatin condensation, caspase activation, and intracellular ROS production. Our data indicate that originally synthesized naringenin derivatives, KUF-1 and KUF-7 differentially regulate the apoptosis of A549 cells via intracellular ROS production coupled with the concomitant activation of the caspase cascade signaling pathway, thereby implying that hydroxylation or substitution at Carbon-7 is critical for the apoptosis-inducing activity of flavonoids.
\end{abstract}

Key words flavonoid; synthetic naringenin derivative; reactive oxygen species; apoptosis; lung cancer; A549

Lung cancer is one of the most common cancers in many countries and the leading cause of cancer deaths in the world accounting for $28 \%$ of all cancer death. ${ }^{1,2)}$ The high mortality of this disease is due to the difficulty of early diagnosis and its high potential to invade locally and metastasize to distant organs. Therefore, there is need for novel diagnosis, treatment, and prevention, against lung cancer.

As the functional compounds of the plants can serve as a starting point for the development of optimal derivatives, scientists are always searching for new medical herbs. Flavonoids are plant pigments which have been detected in all parts of plants and major functional components of many herbal preparations used in traditional medical protocols. ${ }^{3-6}$ Fruits and vegetables, as well as popular beverages such as wine, tea, and coffee, are the main dietary sources of flavonoids. It has been reported that flavonoids show pharmacological effects such as antiviral, ${ }^{7)}$ antitumor, ${ }^{8)}$ antioxidant, $^{9,10)}$ and anti-inflammatory activities. ${ }^{11)}$ They are low molecular weight polyphenolic compounds, which possess a basic 2-phenyl-benzo-gamma-pyrone structure harboring one or more hydroxyl groups. As the result of this basic chemical structure, one of the most obvious features of flavonoids is their ability to quench free radicals via the formation of resonance-stabilized phenoxyl radicals. ${ }^{12)} \mathrm{Re}$ cently, They have attracted much attention because of their broad pharmacological activities, in particular antioxidant activities, and anti-tumorigenic activities. ${ }^{13,14)}$

Flavonoids exert protective effects, which appear to be related to specific structural characteristics. ${ }^{15)}$ Recently, several studies have reported that the differential effects of flavonoids are attributable to substituted functional groups. ${ }^{16,17)}$ We also suggested that the $\mathrm{OH}$ group of the -5 or carbon- 7 of the $\mathrm{C} 6 \mathrm{C} 3 \mathrm{C} 6$ skeleton is the key determinant of the anti-oxidant and anti-apoptotic activities associated with flavonoids. ${ }^{18,19)}$ Therefore, investigations into the structurally related activities of flavonoids are important in terms of our understanding of their differential activities. The association between flavonoid intake and reduced disease risk was originally believed to be the consequence of the anti-oxidant effects of these compounds and recent evidence appears to indicate that flavonoids and their metabolites exert other intracellular effects, including the direct modulation of cell signaling pathways, including the MAPK( Mitogen activated protein kinase) cascade. ${ }^{20-23)}$

In this study, we describe the apoptotic cell death of human lung epithelial carcinoma A549 cells as the result of treatment with synthetic naringenin derivates, including 7-Obenzyl naringenin (KUF-1), 7-O-(m-metoxybenzyl) naringenin (KUF-2), 7-O-(2-naphtylmethyl) naringenin (KUF-5), 7-O-benzoxycarbonylmethyl naringenin (KUF-6), 7-O-(MeOL-Leu-D-Pro-carbonylmethyl) naringenin (KUF-7), and 7-O(MeO-Gly-D-Pro-carbonylmethyl) naringenin (KUF-8) (Fig. 1). The synthetic naringenin derivates were originally generated via the substitution of the carbon-7 of the $\mathrm{C} 3 \mathrm{C} 6 \mathrm{C} 3$ skeleton of naringenin by specific benzyl or amino acid moieties. We analyzed the intracellular levels of reactive oxygen species (ROS), and caspase-3 activation in A549 cells treated with the synthetic naringenin derivates. Our results provide scientific evidence to demonstrate that hydroxylation or substitution at Carbon-7 is critical to the apoptosis-inducing activity of flavonoids, supporting the structurally related activities of flavonoids in apoptosis.

\section{MATERIALS AND METHODS}

Cell Culture Human A549 lung cancer cell line was cultured at $37^{\circ} \mathrm{C}$ in RPMI 1640 medium supplemented with $10 \%$ fetal bovine serum (Hyclone) and 100 units/ml of penicillin/streptomycin.

Materials and Antibodies The $2^{\prime}, 7^{\prime}$-dichloro-fluorescin 
diacetate (DCFH-DA) was purchased from Molecular Probes and the electrophoresis reagents and protein assay kit were acquired from Bio-Rad (Hercules). Antibodies against poly(ADP-ribose) polymerase (PARP), caspase-3 were obtained from Santa Cruz. A natural flavonoid, 5,7,4'-trihydroxy flavanon (naringenin) was obtained from the INDOFINE Chemical Company (NJ, U.S.A.).

Cell Viability Analysis A549 cells were plated at a density of $5 \times 10^{4}$ cells in 96-well plates, and cell viability was evaluated via a conventional 3-(4,5-dimethylthiazol-2-yl)2,5-diphenyl tetrazolium bromide (MTT) reduction assay. The cells were treated with MTT solution (final concentration, $0.25 \mathrm{mg} / \mathrm{ml}$ ) for $2 \mathrm{~h}$ at $37^{\circ} \mathrm{C}$. Dark blue formazan crystals forming in the intact cells were then dissolved with DMSO, and the absorbance was measured at $570 \mathrm{~nm}$ using an ELISA reader. The results were then expressed as percentages of MTT reduction, with the absorbance exhibited by the control cells being arbitrarily set as $100 \%$.

Preparation of Synthetic Naringenin Derivatives For the preparation of 7-O-alkyl naringenin derivatives (KUF-1, -2 , -5 , and -6$), \mathrm{K}_{2} \mathrm{CO}_{3}(1.0 \mathrm{eq})$ was added to a solution of racemic naringenin (1.0 eq) and alkyl bromide (1.0 eq) in $\mathrm{DMF}$ at room temperature. After the resulting mixture was stirred at room temperature for $12 \mathrm{~h}$, the mixture was dissolved in AcOEt and washed with $1 \mathrm{~N} \mathrm{HCl}$ and brine. The organic phase was dried over anhydrous $\mathrm{MgSO}_{4}$, filtered, and concentrated. The crude material was purified by column chromatography (hexane-AcOEt $3: 1$ ) on silica gel to provide $7-O$-alkyl naringenin in $65-50 \%$ yields. For the 7-O-(MeO-L-Leu-L-Pro-carbonylmethyl) naringenin derivative (KUF-7 and -8), $\mathrm{K}_{2} \mathrm{CO}_{3}(1.0 \mathrm{eq})$ was added to a solution of naringenin $(1.0 \mathrm{eq})$, tetrabutylammonium iodide $(1.0 \mathrm{eq})$, and methyl $N$-( $\alpha$-bromoacetyl)-prolinyl-leucinate (1.0 eq) in methylene chloride at room temperature. After the resultant mixture was stirred for $24 \mathrm{~h}$ at room temperature, the reaction mixture was dissolved into AcOEt and washed with $1 \mathrm{~N}$ $\mathrm{HCl}$ and brine. The organic phase was dried over anhydrous $\mathrm{MgSO}_{4}$, filtered, and concentrated. The crude material was purified via column chromatography (hexane-AcOEt 2:1) on silica gel to give $41 \%$ yield. The purities $(>95 \%)$ of products were estimated by NMR. ${ }^{1} \mathrm{H}-\mathrm{NMR}$ spectra were acquired on Bruker $400(400 \mathrm{MHz} 1 \mathrm{H})$ spectrometer using chloroform- $d$ or DMSO- $d_{6}$ as the internal standard.

KUF-1: ${ }^{1} \mathrm{H}-\mathrm{NMR}$ (DMSO- $\left.d_{6}, 400 \mathrm{MHz}\right) 7.45-7.31$ (m, $7 \mathrm{H}), 6.79(\mathrm{~d}, J=8.4 \mathrm{~Hz}, 2 \mathrm{H}), 6.17(\mathrm{~m}, 2 \mathrm{H}), 5.48(\mathrm{dd}, J=12.8$, $2.8 \mathrm{~Hz}, 1 \mathrm{H}), 5.17(\mathrm{~s}, 2 \mathrm{H}), 3.32(\mathrm{dd}, J=13.1,17.1 \mathrm{~Hz}, 1 \mathrm{H})$, $2.72(\mathrm{dd}, J=2.9,17.1 \mathrm{~Hz}, 1 \mathrm{H})$.

KUF-2: ${ }^{1} \mathrm{H}-\mathrm{NMR}\left(\mathrm{CDCl}_{3}, 400 \mathrm{MHz}\right) 7.34-6.86(\mathrm{~m}, 8 \mathrm{H})$, $6.14(\mathrm{~m}, 2 \mathrm{H}), 5.35(\mathrm{dd}, J=13.0,2.9 \mathrm{~Hz}, 1 \mathrm{H}), 5.04(\mathrm{~s}, 2 \mathrm{H})$, $3.82(\mathrm{~s}, 3 \mathrm{H}), 3.08(\mathrm{dd}, J=13.0,17.2 \mathrm{~Hz}, 1 \mathrm{H}), 2.78$ (dd, $J=2.9,17.2 \mathrm{~Hz}, 1 \mathrm{H})$.

KUF-5: ${ }^{1} \mathrm{H}-\mathrm{NMR} \quad\left(\mathrm{CDCl}_{3}, 400 \mathrm{MHz}\right) \quad 7.73-6.70 \quad(\mathrm{~m}$, $11 \mathrm{H}), 6.14(\mathrm{~m}, 2 \mathrm{H}), 5.32(\mathrm{~d}, J=13.0 \mathrm{~Hz}, 1 \mathrm{H}), 5.04(\mathrm{~s}, 2 \mathrm{H})$, 3.09 (dd, J=13.0, $17.2 \mathrm{~Hz}, 1 \mathrm{H}), 2.79$ (dd, $J=2.9,17.2 \mathrm{~Hz}$, $1 \mathrm{H})$.

KUF-6: ${ }^{1} \mathrm{H}-\mathrm{NMR}\left(\mathrm{CDCl}_{3}, 400 \mathrm{MHz}\right) 7.90-6.85(\mathrm{~m}, 9 \mathrm{H})$, $6.16(\mathrm{~m}, 2 \mathrm{H}), 5.31(\mathrm{~m}, 5 \mathrm{H}), 3.07(\mathrm{dd}, J=13.0,17.1 \mathrm{~Hz}, 1 \mathrm{H})$, $2.76(\mathrm{dd}, J=3.0,17.1 \mathrm{~Hz}, 1 \mathrm{H})$.

KUF-7: ${ }^{1} \mathrm{H}-\mathrm{NMR}\left(\mathrm{CDCl}_{3}, 400 \mathrm{MHz}\right) 7.21(\mathrm{~d}, J=8.2 \mathrm{~Hz}$, $2 \mathrm{H}), 6.83(\mathrm{~d}, J=8.2 \mathrm{~Hz}, 2 \mathrm{H}), 5.98(\mathrm{~m}, 2 \mathrm{H}), 5.21(\mathrm{~m}, 1 \mathrm{H})$, $4.59(\mathrm{~m}, 4 \mathrm{H}), 3.71(\mathrm{~s}, 3 \mathrm{H}), 3.70-3.40(\mathrm{~m}, 2 \mathrm{H}), 3.01(\mathrm{~m}$,
1H), 2.65 (m, 1H), $2.05(\mathrm{~m}, 4 \mathrm{H}), 1.63(\mathrm{~m}, 3 \mathrm{H}), 0.87(\mathrm{~m}, 6 \mathrm{H})$.

KUF-8: ${ }^{1} \mathrm{H}-\mathrm{NMR}\left(\mathrm{CDCl}_{3}, 400 \mathrm{MHz}\right) 7.24(\mathrm{~d}, J=7.9 \mathrm{~Hz}$, $2 \mathrm{H}), 6.85(\mathrm{~d}, J=7.9 \mathrm{~Hz}, 2 \mathrm{H}), 6.04(\mathrm{~m}, 2 \mathrm{H}), 5.29(\mathrm{~m}, 1 \mathrm{H})$, $4.67(\mathrm{~m}, 2 \mathrm{H}), 4.15(\mathrm{~m}, 1 \mathrm{H}), 3.97(\mathrm{~m}, 2 \mathrm{H}), 3.70(\mathrm{~s}, 3 \mathrm{H})$, $3.70-3.40(\mathrm{~m}, 2 \mathrm{H}), 3.07(\mathrm{~m}, 1 \mathrm{H}), 2.79(\mathrm{~m}, 1 \mathrm{H}), 2.30-1.60$ (m, 4H).

Analysis of Apoptotic Nuclei by DAPI Staining We conducted DAPI staining for the identification of apoptotic nuclei. A549 cells were collected at $2000 \mathrm{rpm}$ for $5 \mathrm{~min}$, washed once in cold PBS, fixed in ice-cold methanol/acetic acid $(1: 1, \mathrm{v} / \mathrm{v})$ for $5 \mathrm{~min}$, then stained with $0.8 \mathrm{mg} / \mathrm{ml}$ of $4^{\prime}$,6-diamidino-2-phenolindole (DAPI) in darkness. ${ }^{24}$ Morphological changes of nuclei in the apoptotic cells were visually assessed under a Zeiss Axiovert 200 microscope, at the fluorescence of the DAPI region (excitation, $351 \mathrm{~nm}$; emission, $380 \mathrm{~nm}) .^{25,26)}$

Western Blot Analysis Cells in $100 \mathrm{~mm}$ dishes were washed three times in ice-cold phospho-buffered saline (PBS), scraped from the dishes, and then collected in extraction buffer $(1 \%$ Triton X-100, $100 \mathrm{~mm}$ Tris-HCl, $\mathrm{pH} 7.5$, $10 \mathrm{~mm} \mathrm{NaCl}, 10 \%$ glycerol, $1 \mathrm{~mm}$ sodium orthovanadate, $50 \mathrm{~mm}$ sodium fluoride, $1 \mathrm{~mm} p$-nitrophenyl phosphate, $1 \mathrm{~mm}$ PMSF). After the cells had been incubated on ice for $30 \mathrm{~min}$, the lysates were centrifuged and the amount of proteins in the cleared lysates was quantified. An equal amount of proteins was then separated on $10-12 \%$ SDS PAGE gel, and then transferred to nitrocellulose membranes $(0.2 \mathrm{~mm}$, Schleicher and Schuell). These membranes were blocked with $3-5 \%$ non-fat dry milk and $0.1 \%$ Tween 20 in Tris-buffered saline (TBS), and subsequently probed with primary antibody in TBS containing 3\% non-fat dry milk and $0.1 \%$ Tween 20 . The antibody-antigen complexes were then detected using goat anti-mouse IgG or goat anti-rabbit IgG peroxidase conjugates, followed by the use of an enhanced chemiluminescence (ECL) detection kit (Amersham Bioscience).

Measurement of Intracellular ROS Levels Intracellular ROS levels were assessed using the oxidant-sensitive fluorescent probe, DCFHDA, under inverted fluorescence microscopy. Cells grown at $1 \times 10^{6}$ cells per $35 \mathrm{~mm}$ culture dish were maintained for $24 \mathrm{~h}$ in growth medium, then exposed to $5 \mathrm{~mm}$ DCFHDA for $30 \mathrm{~min}$. The cells were washed in PBS, and a cover glass was placed atop the dish. DCF fluorescence (excitation, $488 \mathrm{~nm}$; emission, $520 \mathrm{~nm}$ ) was then imaged on an inverted fluorescence microscope. Intracellular peroxide production was also measured, using DCFHDA coupled with spectrofluorometry. Fluorescence was quantified with a Shimadzu RF5301 PC spectrofluorophotometer, set at an excitation of $504 \mathrm{~nm}$ and an emission of $524 \mathrm{~nm}^{27}$ ) The cells were then exposed to $\mathrm{RB} /$ light, and a $5 \mathrm{~mm}$ stock solution of DCFHDA dissolved in $20 \mu \mathrm{l}$ of DMSO was added to each culture dish $30 \mathrm{~min}$ prior to the assay. After incubation at $37^{\circ} \mathrm{C}$, the cells were washed twice in ice-cold PBS, resuspended in $200 \mu \mathrm{l}$ of PBS, and disrupted by three 10 -s cycles of low-output sonication. The supernatants were then acquired after $10 \mathrm{~m}$ of centrifugation in a microcentrifuge and the crude extracts ( $500 \mu \mathrm{g}$ of protein) were suspended in PBS, after which the fluorescence was recorded.

Statistical Analysis All in-vitro experiments were carried out at least three times with three independent samples. Data were expressed as the mean \pm S.E. A significant difference from the respective controls was assayed using Stu- 


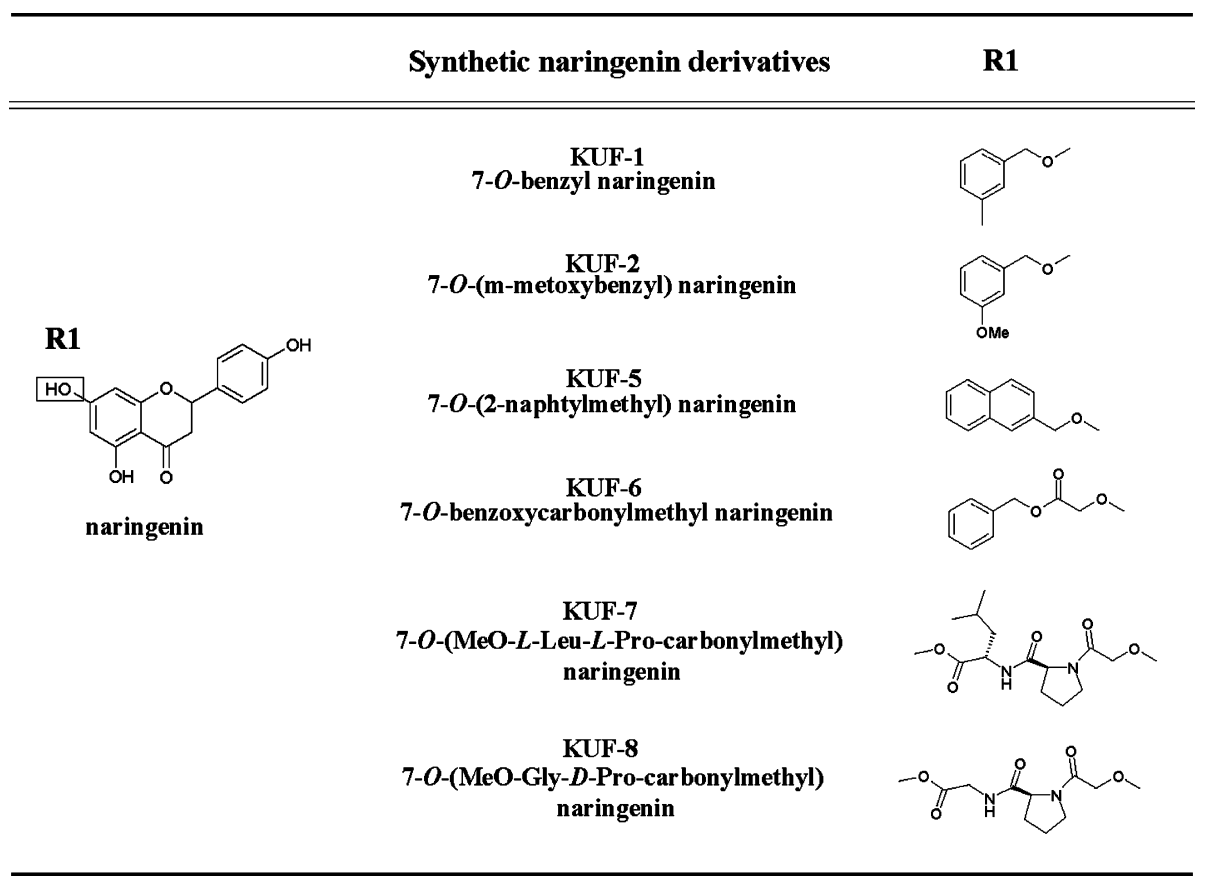

Fig. 1. Structures of Synthetic Naringenin Derivatives

We originally synthesized several synthetic naringenin derivatives including 7-O-benzyl naringenin (KUF-1), 7- $O$-( $m$-metoxybenzyl) naringenin (KUF-2), 7- $O$-(2-naphtylmethyl) naringenin (KUF-5), 7-O-benzoxycarbonylmethyl naringenin (KUF-6), 7-O-(MeO-L-Leu-D-Pro-carbonylmethyl) naringenin (KUF-7), and 7-O-(MeO-Gly-D-Pro-carbonylmethyl) naringenin (KUF-8)

dent's $t$-test for each paired experiment. A $p$-value of $<0.05$ or $<0.01$ was regarded as significant difference.

\section{RESULTS AND DISCUSSION}

Dietary flavonoids, present in edible plants, are known to inhibit tumor cell growth and induce apoptosis in cancer cell lines. Therefore, dietary flavonoids have attracted attention as chemopreventive agents. ${ }^{28}$ ) Thousands of flavonoids are known to occur in nature, and they are both qualitatively and quantitatively one of the largest groups of natural products. ${ }^{29)}$ Flavonoids are polyphenolic compounds harboring 15 carbon atoms and two benzene rings joined by a linear three-carbon chain (Fig. 1). Lots of biological functions of flavonoids have been identified, but there currently exists a lack of evidence for any relationship between the structure-activity relationship (SAR) and apoptosis-inducing activity. As previously reported, we suggested that $\mathrm{OH}$ substitutions on the carbon-7 in the diphenylpropane (C6C3C6) skeleton of the flavonoids might significantly influence the apoptosis-regulating properties of these compounds. ${ }^{18)}$ However, the related structureactivity relationship of the antitumor activity of flavonoids is still unclear.

Naringin, one of the most abundant flavonoids in citrus fruits, has been reported to suppress cytotoxicity and apoptosis in mouse leukemia P388 cells exposed to a typical pro-oxidant, $\mathrm{H}_{2} \mathrm{O}_{2},{ }^{30)}$ or an anticancer drug, cytosine arabinoside (1-L- $d$-arabinofuranosylcytosine; Ara-C) due to its antioxidative properties. ${ }^{31)}$ Orally administered naringin was hydrolyzed by enterobacteria to aglycones such as naringenin before being absorbed. ${ }^{32,33)}$ It has been reported that flavonoid glycosides are metabolized to aglycones, resulting in alteration of their redox potentials, attenuation of hydrophilic properties, and increase in cellular mobility. ${ }^{20)} \mathrm{Re}-$ cently, naringenin has been reported to show anti-proliferative effects and cause apoptotic cell death in various cancer cell lines. ${ }^{34-37)}$ These results indicate that the deglycosylation from naringin to naringenin is change in the activity from suppressor of apoptosis to inducers. In order to characterize the effects of specific substitutions of the carbon-7 of naringenin on apoptosis-regulatory activities, and in an attempt to develop anti-proliferative flavonoid derivatives that would be more effective against lung cancer, we originally synthesized several synthetic naringenin derivatives including 7-O-benzyl naringenin (KUF-1), 7- $O$-( $m$-metoxybenzyl) naringenin (KUF-2), 7-O-(2-naphtylmethyl) naringenin (KUF5), 7-O-benzoxycarbonylmethyl naringenin (KUF-6), 7-O(MeO-L-Leu-D-Pro-carbonylmethyl) naringenin (KUF-7), and 7-O-(MeO-Gly-D-Pro-carbonylmethyl) naringenin (KUF-8) (Fig. 1). Initially, KUF-1 was synthesized to harbor an aromatic group in the Carbon-7 position of naringenin rather than the $\mathrm{OH}$ group. This naringenin derivative, KUF-1, appears to manifest a hydrogen bonding capacity differing from that of the original flavonoid, naringenin. Other synthetic naringenin derivatives, including KUF-2, KUF-5, KUF-6, KUF-7, and KUF-8, were also synthesized in an effort to determine the importance of hydrogen bonding capacity on the effects of the naringenin derivatives. Naringenin derivatives were added to the human A549 lung cancer cell cultures, and their effects on the cell viability of A549 cells were assessed via MTT assays. KUF-1 and KUF-7 most effectively decreased cell viability of A549 cells (Fig. 2A). Different quantities of KUF-1 and KUF-7 were added to the A549 cell cultures, their effects on the cell viability of A549 cells were assessed at several time points via MTT assays. The addition of KUF-1 and KUF-7 appeared to cause the cells to lose cell viability in a dose- and time-dependent manner, and this effect was more profound than was seen with naringenin (Figs. 2B, 
A

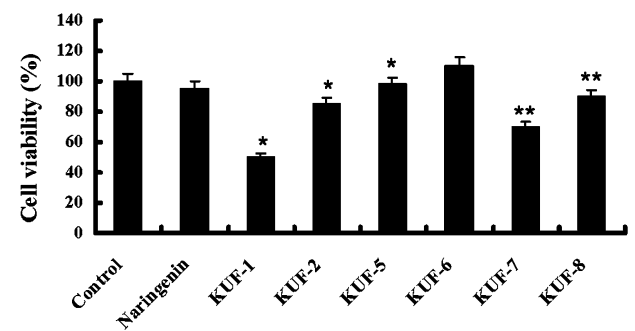

B

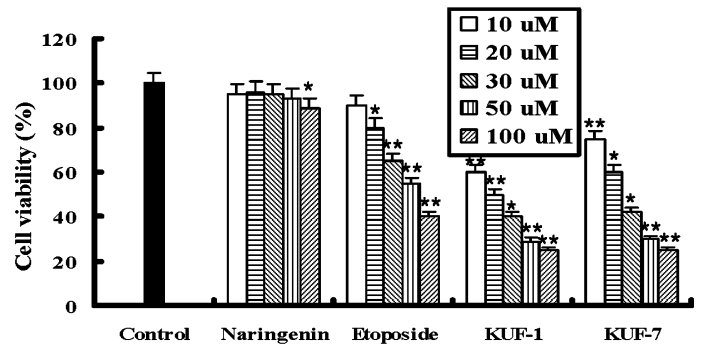

$\mathbf{C}$

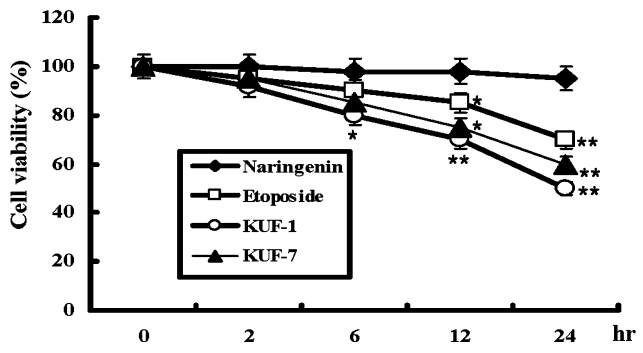

Fig. 2. Loss of Cell Viability by the Synthetic Naringenin Derivatives in Human A549 Lung Cancer Cells

(A) Human lung cancer A549 cells were treated with synthetic naringenin derivatives $(10 \mu \mathrm{M})$ for $48 \mathrm{~h}$ as indicated. Cells treated with a solution devoid of the synthetic flavonoids were used as controls. (B) The A549 cells were treated with the indicated amounts of naringenin derivatives, and cell viability was assessed via MTT assay. Cells were exposed to different concentrations $(10-100 \mu \mathrm{M})$ of KUF-1 or KUF-7 for $48 \mathrm{~h}$. As a control, the cells were treated with an equal amount of DMSO in the absence of flavonoids. (C) Cells were incubated with the indicated phytochemical $(10 \mathrm{M})$ for the indicated time periods. The data are expressed as the means \pm S.E. of values from three independent experiments $(* p<0.05 ; * * p<0.01)$.

C). In particular, KUF-1 and KUF-7 evidenced the most dramatic effects on the cell viability of A549 cells, and their effects were more efficient than that of etoposide, a wellknown apoptosis-inducing anti-cancer drug.

In an attempt to determine whether the addition of KUF-1 or KUF-7 induces apoptotic cell death, DAPI staining of nuclear DNA was conducted in KUF-1 or KUF-7-treated A549 cells. Nuclear condensation and fragmentation became apparent upon exposure to $10 \mu \mathrm{M}$ of KUF-1 or KUF-7 (Fig. 3A). KUF-1 or KUF-7 induced significant increases in apoptotic cell death in the A549 cell cultures. Apoptosis is a type of cell death, and agents with the ability to induce apoptosis in tumors have the potential to be used for antitumor therapy. The apoptotic mechanism has been extensively studied, and activation of caspase 3 and cleaved PARP have been shown to occur in apoptosis. The addition of KUF-1 or KUF-7 induced the cleavage of PARP and the activation of caspase-3 (Fig. 3B). Flavonoids have been shown to induce several biological effects including the apoptosis-inducing activities. ${ }^{38,39)}$ However, the role specific substitutions of the carbon-7 in the apoptosis inducing activity of flavonoid has still not been clearly delineated. Here, we found that treatment of
A

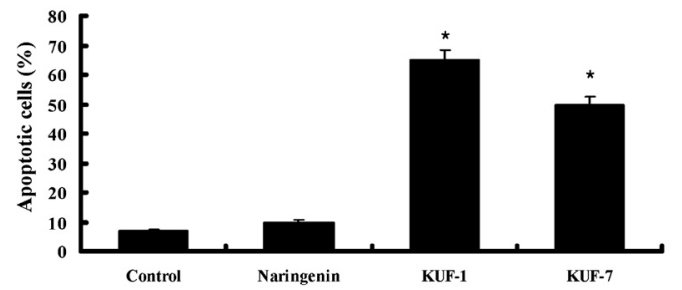

$\mathbf{B}$

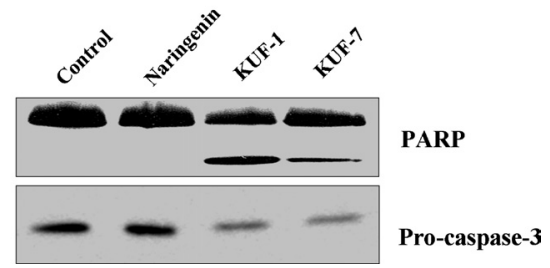

Fig. 3. Apoptotic Cell Death Induced by Treatment of KUF-1 or KUF-7 in A549 Cells

(A) Cells $\left(1 \times 10^{6}\right.$ cells per $\left.\mathrm{ml}\right)$ were cultured in the absence (control) or presence of $10 \mu \mathrm{M}$ KUF-1 or KUF-7. The cells were harvested, fixed with methanol/acetic acid $(1: 1, \mathrm{v} / \mathrm{v})$ then loaded with $0.8 \mu \mathrm{g} / \mathrm{ml}$ DAPI for $5 \mathrm{~min}$. Fluorescence images were acquired via fluorescence microscopy and the cells evidencing apoptotic nuclear morphology were counted. Data are expressed as the means \pm S.E. of values from three independent experiments $(* p<0.05)$. (B) Cells were incubated with KUF-1 or KUF-7 $(10 \mu \mathrm{M})$. The proteins were separated on $10 \%$ SDS-polyacrylamide gel, and then transferred to nitrocellulose membranes. The cleavage of PARP and pro-caspase-3 were assessed via Western blotting. The blots were then re-probed with anti-actin antibody in order to confirm an equal amount of protein loading.

KUF-1 or KUF-7 caused activation of caspase- 3 and cleavage of PARP concomitant with appearance of apoptotic nuclear morphology (Fig. 3).

Several reports have indicated that a host of phenolic phytochemicals, including etoposide and flavonoids, can alter intracellular ROS levels. In order to further elucidate the molecular basis of the apoptotic effect of the synthetic naringenin derivatives, we attempted to determine whether the addition of MNDs induces intracellular ROS production. We measured the levels of intracellular ROS production using the oxidant-sensitive fluorescent dye, DCFH-DA. Apparent intracellular ROS generation was detected after KUF-1 or KUF-7 treatments (Figs. 4A, B). This result strongly indicates that the induction of intracellular ROS generation is involved in the KUF-1 or KUF-7-induced apoptosis of A549 cells. Recently, oxidative damage to the mitochondrial membrane due to increased generation of ROS was reported to play a role in apoptosis. ${ }^{38)}$ Therefore, our findings indicated that the activation of both caspase- 3 activities and intracellular ROS production are a downstream event in the KUF-1 or KUF-7-induced apoptosis of A549 cells. The anti-cancer effects of KUF-1 or KUF-7 were shown to be superior to that of etoposide, a well-known apoptosis-inducing anti-cancer drug. Our results indicate that hydroxylation or substitution at Carbon-7 is crucial with regard to the apoptosis-inducing activity of flavonoids, a finding which supports the notion of the structurally related activities (SAR) of flavonoids in apoptosis.

Acknowledgements This work was supported by the Korea Research Foundation grant funded by the Korea Government(MOEHRD) (KRF-2006-005-J03403 and KRF- 
A

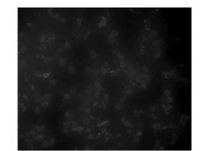

Control

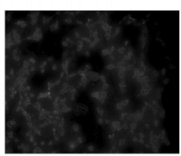

Naringenin

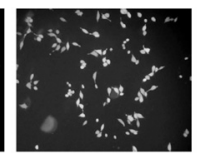

KUF-1

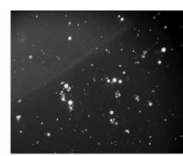

KUF-7
B

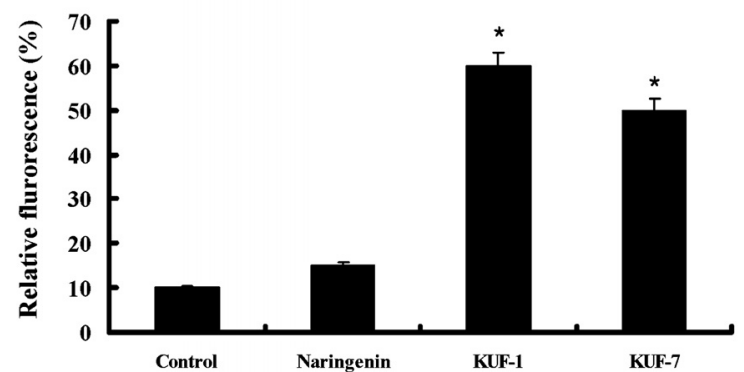

Fig. 4. Increase of Intracellular ROS Production in KUF-1- or KUF-7-Induced Apoptosis of A549 Cells

(A) Cells were incubated with specific phytochemical $(10 \mu \mathrm{M})$ for $12 \mathrm{~h}$, and then intracellular ROS levels were evaluated via fluorescence microscopy with an oxidant-sensitive probe, DCFH-DA. (B) DCF fluorescence in the cells was quantified using a spectrofluorometer (excitation, $504 \mathrm{~nm}$; emission, $524 \mathrm{~nm}$ ). The results were expressed as the means \pm S.E. of values obtained from three separate experiments $(* p<0.05)$.

2006-312-C00627) and, in part, by a Grant from the ERC program of the Korea Science and Engineering Foundation (No. R11-2002-100-01000-0).

\section{REFERENCES}

1) Cheng Y. L., Chang W. L., Lee S. C., Liu Y. G., Lin H. C., Chen C. J., Yen C. Y., Yu D. S., Lin S. Z., Harn H. J., Life Sci., 73, 2383-2394 (2003).

2) Kim P. K., Park S. Y., Koty P. P., Hua Y., Luketich J. D., Billiar T. R., J. Thorac. Cardiovasc. Surg., 125, 1336-1342 (2003).

3) Lin J. K., Chen Y. C., Huang Y. T., Lin-Shiau S. Y., J. Cell. Biochem. Suppl., 28-29, 39-48 (1997).

4) Chen Y. C., Shen S. C., Lee W. R., Hou W. C., Yang L. L., Lee T. J., J. Cell. Biochem., 82, 537-548 (2001).

5) Ko C. H., Shen S. C., Lin H. Y., Hou W. C., Lee W. R., Yang L. L., Chen Y. C., J. Cell. Physiol., 193, 93-102 (2002).

6) Chen Y., Yang L., Lee T. J., Biochem. Pharmacol., 59, 1445-1457 (2000).

7) Beutler J. A., Hamel E., Vlietinck A. J., Haemers A., Rajan P., Roitman J. N., Cardellina J. H., 2nd, Boyd M. R., J. Med. Chem., 41, 2333-2338 (1998).

8) Formica J. V., Regelson W., Food Chem. Toxicol., 33, 1061-1080 (1995).

9) Pietta P. G., J. Nat. Prod., 63, 1035-1042 (2000).
10) Rice-Evans C. A., Miller N. J., Paganga G., Free Radic. Biol. Med., 20 933-956 (1996)

11) Nijveldt R. J., van Nood E., van Hoorn D. E., Boelens P. G., van Norren K., van Leeuwen P. A., Am. J. Clin. Nutr., 74, 418-425 (2001).

12) Bors W., Michel C., Stettmaier K., Biofactors, 6, 399- 402 (1997).

13) Birt D. F., Hendrich S., Wang W., Pharmacol. Ther, 90, 157-177 (2001).

14) Heijnen C. G., Haenen G. R., Oostveen R. M., Stalpers E. M., Bast A., Free Radic. Res., 36, 575-581 (2002).

15) Keinan-Boker L., van Der Schouw Y. T., Grobbee D. E., Peeters P. H., Am. J. Clin. Nutr., 79, 282-288 (2004).

16) Kris-Etherton P. M., Hecker K. D., Bonanome, A., Coval S. M., Binkoski A. E., Hilpert K. F., Griel A. E., Etherton T. D., Am. J. Med., 113 (Suppl, 9B), 71S-88S (2002).

17) Constantinou A. I., Kamath N., Murley J. S., Eur. J. Cancer, 34, 1927-1934 (1998).

18) Lee E. R., Kang Y. J., Kim J. H., Lee H. T., Cho S. G., J. Biol. Chem., 280, 31498-31507 (2005)

19) Lee E. R., Kim J. H., Kang Y. J., Cho S. G., Biol. Pharm. Bull., 30, 32-37 (2007).

20) Williams R. J., Spencer J. P., Rice-Evans C., Free Radic. Biol. Med., 36, 838-849 (2004).

21) Spencer J. P., Rice-Evans C., Williams R. J., J. Biol. Chem., 278 34783-34793 (2003).

22) Spencer J. P., Schroeter H., Crossthwaithe A. J., Kuhnle G., Williams R. J., Rice-Evans C., Free Radic. Biol. Med., 31, 1139-1146 (2001).

23) Schroeter H., Spencer J. P., Rice-Evans C., Williams R. J., Biochem. J., 358, 547-557 (2001).

24) Studzinski G. P., Harrison L. E., Int. Rev. Cytol., 189, 1—58 (1999).

25) Cho S. G., Kim J. W., Lee Y. H., Hwang H. S., Kim M. S., Ryoo K., Kim M. J., Noh K. T., Kim E. K., Cho J. H., Yoon K. W., Cho E. G., Park H. S., Chi S. W., Lee M. J., Kang S. S., Ichijo H., Choi E. J., J. Cell. Biol., 163, 71-81 (2003).

26) Ryoo K., Huh S. H., Lee Y. H., Yoon K. W., Cho S. G., Choi E. J., J. Biol. Chem., 279, 43589-43594 (2004).

27) Royall J. A., Ischiropoulos H., Arch. Biochem. Biophys., 302, 348355 (1993).

28) Kuo S. M., Crit. Rev. Oncog., 8, 47-69 (1997).

29) Depeint F., Gee J. M., Williamson G., Johnson I. T., Proc. Nutr. Soc., 61, 97-103 (2002).

30) Kanno S., Shouji A., Asou K., Ishikawa M., J. Pharmacol. Sci., 92 $166-170$ (2003).

31) Kanno S., Shouji A., Hirata R., Asou K., Ishikawa M., Life Sci., 75, $353-365$ (2004).

32) Ameer B., Weintraub R. A., Johnson J. V., Yost R. A., Rouseff R. L., Clin. Pharmacol. Ther., 60, $34-40$ (1996).

33) Galati G., Chan T., Wu B., O’Brien P. J., Chem. Res. Toxicol., 12 $521-525$ (1999).

34) Kanno S., Tomizawa A., Hiura T., Osanai Y., Shouji A., Ujibe M., Ohtake T., Kimura K., Ishikawa M., Biol. Pharm. Bull., 28, 527—530 (2005).

35) Kawaii S., Tomono Y., Katase E., Ogawa K., Yano M., J. Agric. Food Chem., 47, 3565-3571 (1999).

36) Frydoonfar H. R., McGrath D. R., Spigelman A. D., Colorectal Dis., 5, 149-152 (2003)

37) Virgili F., Acconcia F., Ambra R., Rinna A., Totta P., Marino M., IUBMB Life, 56, 145-151 (2004).

38) Chen Y. C., Shen S. C., Lin H. Y., Biochem. Pharmacol., 66, 11391150 (2003).

39) Shen S. C., Chen Y. C., Hsu F. L., Lee W. R., J. Cell. Biochem., 89, 1044-1055 (2003). 